\title{
Description, measurement and evaluation of tertiary-education food environments
}

\author{
R. Roy ${ }^{1 *}$, L. Hebden ${ }^{1}$, B. Kelly ${ }^{2}$, T. De Gois ${ }^{1}$, E. M. Ferrone ${ }^{1}$, M. Samrout ${ }^{1}$, S. Vermont ${ }^{2}$ and M. Allman-Farinelli ${ }^{1}$ \\ ${ }^{1}$ School of Life and Environmental Sciences, Charles Perkins Centre, University of Sydney, Sydney, NSW 2006, Australia \\ ${ }^{2}$ School of Health and Society, Early Start Research Institute, University of Wollongong, Wollongong, NSW 2500, Australia \\ (Submitted 3 November 2015 - Final revision received 17 January 2016 - Accepted 1 February 2016 - First published online 7 March 2016)
}

\section{Abstract}

Obesity in young adults is an increasing health problem in Australia and many other countries. Evidence-based information is needed to guide interventions that reduce the obesity-promoting elements in tertiary-education environments. In a food environmental audit survey, 252 outlets were audited across seven institutions: three universities and four technical and further education institutions campuses. A scoring instrument called the food environment-quality index was developed and used to assess all food outlets on these campuses. Information was collated on the availability, accessibility and promotion of foods and beverages and a composite score (maximum score $=148$; higher score indicates healthier outlets) was calculated. Each outlet and the overall campus were ranked into tertiles based on their 'healthiness'. Differences in median scores for each outcome measure were compared between institutions and outlet types using one-way ANOVA with post hoc Scheffe's testing, $\chi^{2}$ tests, Kruskal-Wallis $H$ test and the Mann-Whitney $U$ test. Binomial logistic regressions were used to compare the proportion of healthy $v$. unhealthy food categories across different types of outlets. Overall, the most frequently available items were sugarsweetened beverages ( $20 \%$ of all food/drink items) followed by chocolates (12\%), high-energy (>600 kJ/serve) foods (10\%), chips (10\%) and confectionery (10\%). Healthy food and beverages were observed to be less available, accessible and promoted than unhealthy options. The median score across all outlets was 72 (interquartile range $=7$ ). Tertiary-education food environments are dominated by high-energy, nutrient-poor foods and beverages. Interventions to decrease availability, accessibility and promotion of unhealthy foods are needed.

Key words: Measuring instruments: Food environment: Tertiary-education settings: Young adults

Our current obesity-promoting environment is typified by unhealthy food and drinks and has been established as influencing population dietary behaviours ${ }^{(1)}$. The food environment refers to the number, type and accessibility of food outlets as well as the availability, cost, quality and promotion of food and beverage products ${ }^{(2)}$. This environment can provide barriers and/or opportunities for the consumption of a healthy diet, which in turn impacts on diet-related health outcomes ${ }^{(1)}$. Retail food environments are increasingly considered influential in determining dietary behaviours and health outcomes ${ }^{(3)}$. By addressing the food environment, there is potential to encourage selection of healthier foods and beverages. Specifically, measuring food environments would allow for the identification of possible intervention points to improve the access to, availability of, decrease costs and increase promotion of healthy food products $^{(4)}$. The limited quality of food in tertiary-education settings provides evidence to support initiatives to improve the campus food environment ${ }^{(5-7)}$.

A large proportion of young adults attend tertiary-education institutions. In 2014, $2 \cdot 3$ million students were enrolled in the UK with $38.2 \%$ of students aged between 19 and 24 years ${ }^{(8)}$. In the USA, in 2014, over 18 million students aged 15-24 years were enrolled in over 4000 colleges and universities ${ }^{(9)}$. In May 2014, $1 \cdot 2$ million people aged 15-19 years and 689200 people aged 20-24 years were enrolled in colleges and universities in Australia ${ }^{(10)}$. The high attendance in tertiary institutions and the often closed nature of these environments in the provision of foods and beverages to students and staff, therefore, have the substantial potential to influence dietary behaviours in this population.

Young adults experience the fastest rates of weight gain across the life course, which is likely to increase because of the obesity-promoting environments in recent years ${ }^{(11)}$. Their reliance on convenience foods prepared outside the home due to lack of time and low cost or value promotions make them vulnerable to diets of poor nutritional quality ${ }^{(12)}$. The tertiary-education setting therefore provides an opportunity to intervene to create more health-promoting food environments and address their observed low intakes of fruits and vegetables, higher intakes of energy-dense, nutrient-poor foods and drinks and increased risk for excess weight gain ${ }^{(13-15)}$.

Abbreviations: IQR, interquartile range; QI, quality index; SES, socio-economic status; TAFE, technical and further education.

* Corresponding author: R. Roy, email rroy3593@uni.sydney.edu.au 
There is a lack of information and tools available to measure and describe organisational food environments such as tertiaryeducation settings and the potential for these to influence the diet quality of young adults ${ }^{(3)}$. Despite increasing awareness of the role that food environments play in dietary behaviour, most studies have focused on residential neighbourhoods. Researchers have applied tools to the retail food environment setting to classify how closely the foods available in these settings correspond with dietary guidelines, such as the healthy eating index ${ }^{(16-18)}$. However, these tools do not assess product promotion and degree of accessibility ${ }^{(19)}$. These additional factors are essential in comprehensively analysing the food environment $^{(4)}$. Existing tools that measure a range of healthrelated environmental features informed the development of the proposed food environment measure in this study ${ }^{(20-23)}$.

This study aimed to develop and validate a composite scoring system known as the food environment-quality index (QI) to assess the nutritional quality of retail food outlets in the tertiary-education setting. This incorporates information on food availability, accessibility and promotion from food environment audits. We measured the difference in food environment-QI scores between the two types of educational institutions (university $v$. technical and further education (TAFE)) and between different food outlet types (e.g. takeaway outlet $v$. convenience stores).

\section{Methods \\ Design and sampling}

Cross-sectional audits of all food outlets were conducted by four nutrition research students across three large university campuses and four TAFE campuses in New South Wales (NSW), Australia, between March 2014 and October 2014. In Australia, TAFE provide vocational tertiary-education diplomas/ certificates similar to community colleges. Institutions were selected on the basis of the highest enrolment numbers across Sydney (two universities and three TAFE) and regional NSW (one university and one TAFE) ${ }^{(24,25)}$. Socio-Economic Indexes for Areas (SEIFA) is used in Australia to rank relative socioeconomic advantage and disadvantage using postal codes and were used to define the socio-economic status (SES) of the institutions $^{(26)}$. A low SEIFA score indicates greater social deprivation. The geographical boundaries of each campus were outlined, and all existing food outlets identified and mapped for auditing using commercially available geographic data corroborated with the field observations of available outlets ${ }^{(3)}$. A taxonomy of food outlets was adapted to categorise the type of food outlet as café/restaurant, convenience store, coffee cart, independent takeaway, franchise takeaway, vending machine or bar/pub (see online Supplementary Appendix S1) ${ }^{(27)}$. This research was exempt from institutional ethics review as no human subjects were involved.

\section{Data collection}

A purpose-designed audit tool (see online Supplementary Appendix S2) was developed to assess the availability, accessibility and promotion of foods and beverages across all types of food outlets within the university and TAFE campuses $^{(28-30)}$. A recently published review of existing methods and the measure developed by Kelly et al. for assessing food environments informed the development of the audit tool $^{(4,23,27)}$. The three outcome measures assessed were defined by the researchers (Table 1) based on existing literature, and specific criteria were formulated to improve/increase intercoder reliability ${ }^{(27)}$. Before commencement of the audits, two nutrition research students independently audited two randomly selected food outlets and two vending machines to pilot the audit tool and calculate inter-coder reliability. Percentage agreement between coders across all indicators (availability, accessibility and promotions) was found to be $96 \%$. However, upon discussion of discrepancies between coders, a final intercoder reliability score of $99 \%$ was reached. On the basis of this pilot, the only amendment to the coding tool was to separate full-fat and reduced/low-fat yogurts on the basis of their differing SFA content (see online Supplementary Appendix S1).

\section{Data scoring}

The audit tool comprised a list of healthier and unhealthy food and beverage items (online Supplementary Appendix A2). A positive scoring system known as the food environment-QI was developed whereby 1 point was awarded if a healthier item was available, easily accessible or promoted within a food outlet. Similarly, 1 point was awarded if an unhealthy item was not available, not easily accessible or not promoted. Thus, a higher score received by a food outlet indicated a healthier food environment. The maximum achievable score was 148 . Foods were classified as healthy and unhealthy using criteria already developed for use in schools, which outline the type and frequency of foods and drinks permitted for sale using the trafficlight system of green (eat frequently as healthy), amber (eat occasionally) and red foods (eat rarely) ${ }^{(31)}$. There are ten categories (sugary drinks, diet drinks, dairy drinks, other, chocolate and confectionery, high-energy snacks, lower-energy snacks, fruits and nuts, healthy meals such as with vegetables as the major component and less-healthy meals) across which the food outlets are scored. For example, under the high-energy snack category (a less-healthy category), if an outlet made chips/extruded snacks ( $>600 \mathrm{~kJ} / \mathrm{serve}$ ) available, then it would receive a score of 0 for availability. However, if chips/extruded snacks (>600 kJ/serve) were not available, then it would receive a score of 1 . This was the same scoring method used for accessibility (i.e. $0=$ highly accessible, $1=$ less accessible) and promotions (i.e. $0=$ promoted, $1=$ not promoted). Alternatively, under the lower-energy snacks category, the opposite scoring system was used - for example, muesli bars $(<600 \mathrm{~kJ} /$ serve $)$ were scored as follows $-0=$ not available, $1=$ available; $0=$ less accessible, $1=$ highly accessible; and $0=$ not promoted, 1 = promoted (see Table 5). Cut-off points for defining an outlet as 'healthy', 'intermediate' and 'unhealthy' were determined using the spread of the data by dividing the total scores under each measure into tertiles. A food outlet or vending machine was indicated as (1) 'healthy' if the total food environment-QI score achieved was above 86 , as (2) 'unhealthy' if the total score 
was below 70 and as (3) 'intermediate' for a score equal to or between 70 and 86 . Separate total scores were also calculated for the individual indicators of availability, accessibility and promotions. Tertile cut-off points for defining healthier, intermediate and less-healthy outlets were determined using total scores for each of these individual indicators.

\section{Data analysis}

Data were entered into SPSS for Windows version 22.0. Graphs were generated to represent the relative ranking of scores within each indicator (availability, accessibility and promotion) as well as the composite food environment-QI healthiness scores. The median, interquartile range (IQR) and range were computed for each of the three outcome measures within each institution and outlet type, and box plots were generated for composite scores. Differences in scores of food outlets and vending machines according to availability, accessibility and promotion were assessed using one-way ANOVA with post hoc Scheffe's testing. The Kruskal-Wallis $H$ test was used to compare median scores between (1) tertiary institutions and (2) outlet types, and the Mann-Whitney $U$ test used to compare medians between the type of institution (universities and TAFE) to determine any differences in healthiness. The percentage of healthy and/or less-healthy food products available, accessible and promoted in each of these outlets was calculated. Healthy food categories included lower-energy snacks, fruits and nuts and diet drinks ( $n$ 24) (see online Supplementary Appendix S2). Unhealthy food categories included sugary drinks, dairy drinks, chocolate and confectionery and high-energy snacks ( $n$ 26) (see online Supplementary Appendix S2). $\chi^{2}$ tests were used to compare these non-parametric data across different types of food outlets. A logistic regression was performed to ascertain the likelihood of individual product categories available, accessible and promoted in higher scoring outlets (based on highest tertile) compared with lowest scoring outlets (based on lowest tertile) with associated OR reported. $P$ values $<0.05$ were considered to be significant.

\section{Results}

The sample included seven tertiary-education institutions with 252 food outlets (208 were located in universities and forty-four in TAFE), with an equal distribution of urban and regional institutions. The median total score for all seven outlets was 72 and scores ranged from 53 to 90. Table 2 provides a summary of the SES, demographics and number of different types of food outlets in the institutions audited. It should be noted that socio-economic measures show that, although certain universities are in high-SES areas, they have a greater diversity of SES than their surroundings in comparison with TAFE, which enrol locally. Higher-income educational institutions such as urban universities with higher enrolment numbers in high-SES areas had wider variety of outlet types available in comparison with the typical cafeteria and vending machine offerings in lower- and medium-SES area $\mathrm{TAFE}^{(24-26)}$. Institutions in lower-SES areas lacked relatively higher scoring outlets such as bars/pubs and franchise takeaway stores but also had fewer convenience stores and vending machines, unlike institutions in higher-SES urban areas (Table 2). Vending machines in institutions located in high-SES areas had greater mean number of unhealthy items available. Young adults attending institutions based in lower-SES areas would still be exposed to one outlet per 1000 students on average (Table 2).

\section{Food environment-quality index scores}

There was no statistically significant difference in food environment-QI scores between the different institution types $\left(\chi^{2}(2)=10 \cdot 066, \quad P=0 \cdot 122\right)$. Overall, there was a difference in food environment-QI scores across the different types of food outlets $\left(\chi^{2}(2)=15 \cdot 739, P=0.015\right)$. Post hoc testing revealed that this difference specifically related to convenience stores (median food environment-QI score $=65$ ) and franchise takeaway outlets (median food environment-QI score $=76$ ) $\left(\chi^{2}(2)=-113 \cdot 38, P=0 \cdot 038\right)$.

Table 1. Summary of food environment-healthy eating index outcome measures

\begin{tabular}{|c|c|c|}
\hline Outcome measures & Definitions & Criteria and/or examples \\
\hline Availability & $\begin{array}{l}\text { Food and drink products that are present and ready for } \\
\text { purchase within a food outlet or vending machine }\end{array}$ & $\begin{array}{l}\text { The presence of sugar-sweetened beverages in certain outlets } \\
\text { The presence of fresh fruit }\end{array}$ \\
\hline \multirow[t]{2}{*}{ Accessibility } & $\begin{array}{l}\text { The ease with which food and drink products can be } \\
\text { obtained by consumers }{ }^{(14)}\end{array}$ & $\begin{array}{l}\text { Highly accessible products include: } \\
\text { - products near cash registers } \\
\text { - } \text { within-floor displays } \\
\text { - self-serve fridges }\end{array}$ \\
\hline & & $\begin{array}{l}\text { Difficult to access products include: } \\
\text { - products behind counters } \\
\text { - made-to-order foods and drinks }\end{array}$ \\
\hline Promotion & $\begin{array}{l}\text { Any form of display, rebate, coupon or sale that is used } \\
\text { to announce and encourage purchasing of food and } \\
\text { drink products }{ }^{(2,15)}\end{array}$ & $\begin{array}{l}\text { - Must be A4 size or larger } \\
\text { - includes signs, posters, stickers, banners, billboards, table tents, } \\
\text { end-of-aisle displays }\end{array}$ \\
\hline
\end{tabular}




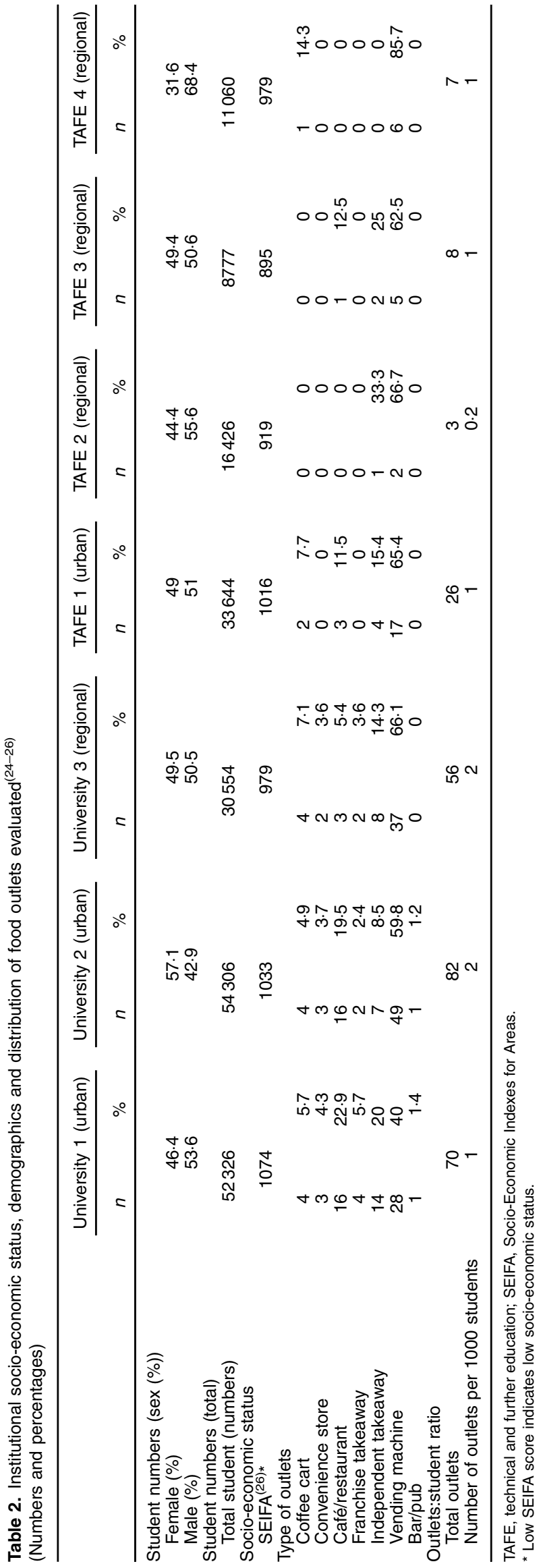

\section{Availability}

Comparing availability by institution type, universities and TAFE showed similar median scores $(23, \mathrm{IQR}=4$ and $22 \cdot 5, \mathrm{IQR}=4$, respectively; $U=4318.5, \quad P=0.555$ ) (Table 3 ). There was no difference in availability scores across institutions $\left(\chi^{2}(6)=9 \cdot 278, P=0.159\right)$ (Table 4). There was no significant difference in the distribution of availability scores across different outlet types $\left(\chi^{2}(6)=14 \cdot 877, P=0 \cdot 21\right)$. Bars/pubs and franchise takeaway stores had the highest medians (27 and 26 out of a possible 49, respectively) and convenience stores the lowest (21) (Fig. 1).

Overall, convenience stores and vending machines scored low in availability because they had five times the odds of providing high-energy snacks (chips/crisps, confectionery, chocolates/lollies, biscuits, baked goods and muesli bars) and sugar-sweetened beverages (OR $=5.5 ; 95 \%$ CI 1.21, 25.05; $P<0.05)$. When comparing the percentage of foods and beverages made available for high-scoring outlets and lowscoring outlets (Table 5), 'healthier' outlets based on availability score (with an availability score $\geq 25, n 84$ ) made water (highscoring outlets $86 v$. 44\% low-scoring outlets), diet soft drinks (76 v. 45\%), salads (25 v. 18\%) and hot mixed dishes with vegetables as the major component $(25 v .21 \%)$ more available than low-scoring outlets (defined as outlets with an availability score $\leq 21, n 82$ ). They also had a lower availability of sports

Table 3. Comparison of food environment-healthy eating index scores by type of institution

(Medians and interquartile ranges (IQR))

\begin{tabular}{lcccccc}
\hline & \multicolumn{5}{c}{ Institution type } \\
\cline { 2 - 6 } & \multicolumn{2}{c}{ University } & & TAFE \\
\cline { 2 - 3 } \cline { 5 - 7 } & Median & IQR & & Median & IQR & $P$ \\
\hline Total score & 72 & 8 & 71 & 10 & $>0.05$ \\
Availability & 23 & 4 & 23 & 4 & \\
Accessibility & 24 & 4 & 24 & 4 & \\
Promotion & 25 & 1 & 25 & 2 & \\
\hline
\end{tabular}

TAFE, technical and further education.

Table 4. Analysis of outlet ( $n$ 252) total scores across examined tertiaryeducation institutions $(n 7)$

(Medians and interquartile ranges (IQR))

\begin{tabular}{lccccc}
\hline & \multicolumn{5}{c}{ Median scores } \\
\cline { 2 - 6 } Institutions & Availability $^{*}$ & Accessibility & Promotions & Total§ & IQR \\
\hline University (1) & 24 & $24 \cdot 5$ & 25 & 73 & 7 \\
University (2) & 23 & 23 & 24 & 70 & 8 \\
University (3) & 23 & 23.5 & 25 & 70 & $6 \cdot 75$ \\
TAFE (1) & $22 \cdot 5$ & 24 & 25 & 71.5 & $9 \cdot 25$ \\
TAFE (2) & 21 & 22 & 24 & 66 & 0 \\
TAFE (3) & 24 & 25 & 25 & 74 & 11 \\
TAFE (4) & 24 & 24 & 25 & 71 & 13 \\
\hline
\end{tabular}

TAFE, technical and further education.

* No difference in availability scores $\left(X^{2}(6)=9.278, P=0.159\right)$ between institutions. † Difference in accessibility scores $\left(X^{2}(6)=12.897, P=0.045\right)$ between institutions. $\ddagger$ No difference in promotion scores $\left(X^{2}(6)=10.567, P=0.103\right)$ between institutions. $\S$ Kruskal-Wallis $H$ test showed that there was no statistically significant difference in food environment score between the different institutions, $X^{2}(2)=10.066, P=0.122$. 




Fig. 1. Comparison of food environment-quality index scores across three outcome measures by types of food outlets using a graph displaying the median of availability, accessibility, promotion and total scores across examined outlet types. The Kruskal-Wallis $H$ test showed that there was a statistically significant difference in total food environment scores between the different types of food outlets, $X^{2}$ test $=15.739, P=0.015$ (availability $P<0.05(\square)$, accessibility $P<0.05$ (四), promotions $P>0.05$ (

drinks (57 v. 81\%) and fruit drinks (59v. $77 \%)$. Less-healthy outlets had a greater number of high-energy snacks available including chocolate (low-scoring outlets 95 v. $22 \%$ high-scoring outlets), confectionery/lollies (98v.23\%), chips/extruded snacks $>600 \mathrm{~kJ} /$ serve $(95 v .22 \%$ ), sweet biscuits $>600 \mathrm{~kJ} / \mathrm{serve}$ (88 $v$. $21 \%$ ), muesli bars $>600 \mathrm{~kJ} /$ serve $(95 v .55 \%$ ) and cakes/muffins/ sweet pastries $>900 \mathrm{~kJ} /$ serve $(83 v .52 \%)$. This trend was also observed with higher-energy meals where deep-fried takeaways (87 v. 71\%), pies and pastries (93 v. 74\%), pizzas (99 $v$. $79 \%)$ and hamburgers/hot dogs (94 $v .74 \%)$ were on sale more frequently in lower-scoring outlets. The above-mentioned foods and beverages also account for the most highly available products across the total outlet sample.

\section{Accessibility}

High-scoring outlets had accessibility scores of 25 or greater and low-scoring outlets had scores of 21 or less, out of a possible score of 49. A significant difference in accessibility scores was found between the seven institutions $\left(\chi^{2} \quad(6)=12.897, \quad P=0.045\right)$ (Table 3). However, universities and TAFE produced identical median scores under accessibility (24) and IQR (4), suggesting no difference in accessibility scores across institution type ( $U=4198.5$, $P=0.381$ ) (Table 4). Differences were seen in accessibility scores across outlet types $\left(\chi^{2}(6)=26 \cdot 131, P=0 \cdot 000\right)$ (Fig. 1). Convenience stores received the lowest set of scores, demonstrating more accessibility to unhealthy products ( median $=20 \cdot 5$ ).
Vending machines also received a lower median score, whereas takeaway stores received the highest scores (25) (Fig. 1).

Convenience stores and vending machines were in the bottom tertiles for scores across accessibility as they had more than thirteen times the odds of providing easily accessible, high-energy snacks (chips/crisps, confectionery, chocolates/ lollies, biscuits, baked goods and muesli bars) and sugarsweetened beverages than food outlets in the top tertiles such as takeaway (franchise) outlets (OR $=13 \cdot 6$; $95 \%$ CI 1.46, 126.5; $P<0.05$ ). Products made more easily accessible in low-scoring outlets (typically in convenience stores and vending machines) (Table 5) included chips/extruded snacks $>600 \mathrm{~kJ} /$ serve $(97 \%$ low-scoring outlets have these $v .19 \%$ high-scoring outlets), chocolate (96v. 20\%), confectionery/lollies (98v. 20\%), sweet biscuits $>600 \mathrm{~kJ} /$ serve (93 v. 24\%), muesli bars $>600 \mathrm{~kJ} /$ serve (96 v. 55\%), sugary energy drinks (88v. 66\%), fruit drinks (95 v. 72\%) and sports drinks (90 v. 66\%). A total of 143 of 252 outlets made water easily accessible, which included forty-three of the ninety-nine top-scoring outlets in comparison with only nineteen of the ninety-four low-scoring outlets. There was also a high accessibility of dried fruits/nuts in vending machines and self-serve fridges in cafes and coffee carts of high-scoring outlets (46\%) but not in low-scoring outlets (6\%).

\section{Promotions}

A total of fifty-three high-scoring outlets and ninety-seven low-scoring outlets were identified for promotion scores, with 
Table 5. Percentage of foods and beverages made available, accessible and promoted in the food outlets across the top and bottom tertiles

\begin{tabular}{|c|c|c|c|c|c|c|c|}
\hline \multirow[b]{2}{*}{ Foods and drinks } & \multirow[b]{2}{*}{ Foods } & \multicolumn{2}{|c|}{ Availability } & \multicolumn{2}{|c|}{ Accessibility } & \multicolumn{2}{|c|}{ Promotions } \\
\hline & & $\begin{array}{l}\text { Top tertile } \\
(\%)\end{array}$ & $\begin{array}{l}\text { Bottom tertile } \\
\qquad(\%)\end{array}$ & $\begin{array}{l}\text { Top tertile } \\
\text { (\%) }\end{array}$ & $\begin{array}{l}\text { Bottom tertile } \\
\qquad(\%)\end{array}$ & $\begin{array}{l}\text { Top tertile } \\
(\%)\end{array}$ & $\begin{array}{l}\text { Bottom tertile } \\
\qquad(\%)\end{array}$ \\
\hline \multirow[t]{3}{*}{ Diet drinks } & Diet soft drinks & 76 & 45 & 40 & 31 & 11 & 8 \\
\hline & Diet energy drinks & 12 & 10 & 10 & 5 & 1 & 0 \\
\hline & Diet flavoured water/iced tea & 6 & 4 & 4 & 2 & 0 & 0 \\
\hline \multirow[t]{5}{*}{ Dairy drinks } & Plain milk (reduced fat/skimmed) & 6 & 4 & 3 & 2 & 0 & 0 \\
\hline & Plain milk (full cream) & 88 & 96 & 93 & 98 & 94 & 100 \\
\hline & Flavoured milk (<1600 kJ/serve) & 30 & 17 & 17 & 13 & 17 & 3 \\
\hline & Yogurt (reduced/low fat) & 10 & 8 & 4 & 2 & 2 & 1 \\
\hline & Yogurt (full fat) & 78 & 92 & 88 & 98 & 96 & 98 \\
\hline \multirow{8}{*}{$\begin{array}{l}\text { Lower-energy } \\
\text { snacks }\end{array}$} & Muesli bars $(<600 \mathrm{~kJ} /$ serve $)$ & 5 & 4 & 4 & 3 & 0 & 0 \\
\hline & Savoury biscuits (<600 kJ/serve) & 4 & 1 & 3 & 2 & 0 & 0 \\
\hline & Sweet biscuits ( $<600 \mathrm{~kJ} /$ serve) & 4 & 1 & 2 & 1 & 0 & 0 \\
\hline & Rice crackers (<600 kJ/serve) & 2 & 0 & 2 & 0 & 0 & 0 \\
\hline & Ice cream $(<600 \mathrm{~kJ} /$ serve $)$ & 5 & 6 & 6 & 1 & 2 & 2 \\
\hline & Popcorn (<600 kJ/serve) & 4 & 1 & 5 & 2 & 2 & 0 \\
\hline & Chips/extruded snacks (<600 kJ/serve) & 18 & 4 & 24 & 2 & 4 & 0 \\
\hline & Cakes/muffins/sweet pastries (<900 kJ/serve) & 6 & 1 & 4 & 1 & 2 & 0 \\
\hline \multirow{4}{*}{$\begin{array}{l}\text { Chocolate and } \\
\text { confectionery }\end{array}$} & Chocolate & 22 & 95 & 20 & 96 & 91 & 98 \\
\hline & Ice cream (>600 kJ/serve) & 77 & 95 & 87 & 97 & 84 & 98 \\
\hline & Confectionery/lollies & 23 & 98 & 20 & 98 & 93 & 100 \\
\hline & Fruit chews/straps & 70 & 96 & 72 & 97 & 96 & 100 \\
\hline \multirow{8}{*}{$\begin{array}{l}\text { High-energy } \\
\text { snacks }\end{array}$} & Muesli bars (>600 kJ/serve) & 55 & 95 & 55 & 96 & 96 & 98 \\
\hline & Rice crackers (>600 kJ/serve) & 94 & 99 & 96 & 98 & 97 & 100 \\
\hline & Popcorn (>600 kJ/serve) & 95 & 99 & 95 & 98 & 97 & 100 \\
\hline & Iced confection (>300 kJ/serve) & 85 & 96 & 91 & 98 & 97 & 100 \\
\hline & Savoury biscuits (>600 kJ/serve) & 79 & 99 & 80 & 98 & 97 & 98 \\
\hline & Sweet biscuits (>600 kJ/serve) & 21 & 88 & 24 & 93 & 96 & 100 \\
\hline & Cakes/muffins/sweet pastries (>900 kJ/serve) & 52 & 83 & 74 & 95 & 87 & 94 \\
\hline & Chips/extruded snacks (>600 kJ/serve) & 22 & 95 & 19 & 97 & 47 & 100 \\
\hline \multirow[t]{4}{*}{ Healthy meals } & Sushi rolls & 6 & 2 & 1 & 0 & 6 & 1 \\
\hline & Salads & 25 & 18 & 3 & 1 & 9 & 3 \\
\hline & Sandwiches & 30 & 20 & 5 & 1 & 17 & 9 \\
\hline & Hot mixed dishes (veg the major component) & 25 & 21 & 1 & 1 & 8 & 4 \\
\hline \multirow[t]{5}{*}{ Less-healthy meals } & $\begin{array}{l}\text { Deep-fried takeaway foods (e.g. hot chips, } \\
\text { chiko rolls) }\end{array}$ & 71 & 87 & 95 & 99 & 91 & 96 \\
\hline & Hamburgers/hot dogs & 74 & 94 & 94 & 99 & 92 & 98 \\
\hline & $\begin{array}{l}\text { Hot mixed dishes (veg not the major } \\
\text { component) }\end{array}$ & 61 & 74 & 93 & 98 & 86 & 92 \\
\hline & Pies and pastries (savoury) & 74 & 93 & 89 & 98 & 93 & 100 \\
\hline & Pizza & 79 & 99 & 94 & 99 & 95 & 100 \\
\hline \multirow[t]{4}{*}{ Fruit and nuts } & Fresh fruit & 26 & 18 & 9 & 7 & 6 & 1 \\
\hline & Tinned fruit & 0 & 2 & 1 & 0 & 0 & 0 \\
\hline & Dried fruit/nuts/seeds & 6 & 41 & 46 & 6 & 0 & 0 \\
\hline & Other please (specify) & 1 & 1 & 0 & 2 & 0 & 0 \\
\hline \multirow[t]{6}{*}{ Sugary drinks } & Sugar-sweetened energy drinks & 56 & 70 & 66 & 88 & 88 & 100 \\
\hline & Sugar-sweetened flavoured water/iced tea & 43 & 51 & 64 & 73 & 81 & 98 \\
\hline & Sugar-sweetened soft drinks & 49 & 18 & 56 & 68 & 77 & 94 \\
\hline & Flavoured milk (>1600 kJ/serve) & 70 & 92 & 84 & 96 & 93 & 98 \\
\hline & Sports drinks & 57 & 81 & 66 & 90 & 91 & 98 \\
\hline & Fruit drinks & 59 & 77 & 72 & 95 & 95 & 100 \\
\hline \multirow[t]{2}{*}{ Other } & Water (including plain, mineral, soda water) & 86 & 44 & 20 & 43 & 62 & 10 \\
\hline & $100 \%$ fruit or vegetable juice & 40 & 30 & 19 & 10 & 13 & 2 \\
\hline
\end{tabular}

greater promotion of unhealthy foods. However, based on tertiles for promotion scores, a high-scoring outlet required a score of 26 or greater and low-scoring outlets were defined to score 24 or less, showing little variation within promotion scores across the sample. Similar medians (24-25), IQR (1-2) and dispersion of data were produced between institutions and minimal variations within institutions (Tables 3 and 4). Overall, there was no difference in promotion scores across institutions $\left(\chi^{2}(6)=10 \cdot 567, P=0 \cdot 103\right)$. There were no differences in promotion scores across institution type $(U=4416 \cdot 5, P=0.703)$. No significant differences were observed in promotion scores across outlet type $\left(\chi^{2}(6)=7 \cdot 572, P=0 \cdot 271\right)$ (Fig. 1).

Low-scoring outlets were not highly likely to use strategic price promotions such as two-for-one deals of deep-fried foods, savoury pastries, pizza and mixed dishes with lack of vegetables in takeaway outlets (independent local) and use posters and signage promoting unhealthy brand names of sugar-sweetened drinks, crisps and confectionery in vending machines and 
convenience stores (OR $=0.02 ; 95 \%$ CI 0.00, 0.036; $P<0.05$ ). However, top tertile outlets that scored high under promotions promoted water (high-scoring outlets $62 v$. 10\% low-scoring outlets) and flavoured milk $<1600 \mathrm{~kJ} /$ serve more regularly (17 $v$. $3 \%$ ), particularly observed on the exterior of vending machines (Table 5). Convenience stores and vending machine exteriors showed high promotion of chips/extruded snacks $>600 \mathrm{~kJ} /$ serve in low-scoring outlets (100 v. 47\% high-scoring outlets). Sugar-sweetened soft drinks (94 $v .77 \%$ ), flavoured water/iced tea (98v. $81 \%)$, ice cream $>600 \mathrm{~kJ} /$ serve $(98 v .84 \%)$ and energy drinks (100 v. 88\%) were all more highly promoted in low-scoring outlets. The most frequent promotion strategy was the use of banners and posters to advertise well-known brand names and their associated products.

\section{Discussion}

This study presents results regarding food environments by using a new audit tool to evaluate and measure environmental factors such as availability, accessibility, promotion and nutritional quality that influence food choice among young adults. Previous studies in the USA reported on food quality and availability in eighty-one stores across fifteen institutions including five with more than 30000 students and two technical colleges $^{(5)}$. However, only $17 \%$ of the stores were actually on campus. It was reported that convenience stores on campus had less availability of many healthy items than grocery stores off campus, including low-fat products, whole-grain cereals, fruits and vegetables. Similarly, campus dining halls provided limited support for good nutrition, and snack machines provided salty snacks such as chips, pretzels and candy (including chocolate) $^{(6)}$. Our results revealed that non-caloric beverages were most available than in the USA, which showed that sugar-sweetened beverages were twice as likely to be available in vending machines ${ }^{(7)}$. This is the first systematic attempt to measure indicators of tertiary institutions' food environment and compare these across campuses and institution types in its entirety. These results show that tertiary food environments are not healthy as the median availability, accessibility and promotion scores of outlets fell consistently (approximately 50\%) below the possible maximum score. The majority of food products available, accessible and promoted across the outlets in the seven institutions fell into the high-energy category over low-energy category. High-scoring outlets offered healthy products (e.g. sandwiches, salads and mixed dishes with vegetables as the main component) and low-energy snacks and water. Low-scoring outlets had more energy-dense and less-healthy foods (e.g. deep-fried foods and mixed dishes with the lack of vegetables), high-energy snacks and sugar-sweetened beverages. This is consistent with existing research showing that the 'obesogenic' food environment is typified by the high availability of energy-dense, nutrient-poor foods and drinks relative to healthier options and that very few vending machines offer healthy food or drink products ${ }^{(7,27,28,32-34)}$.

There were no differences by institution types in food environment-QI scores. Two universities produced larger ranges than the other institutions, showing more variation within their outlets. A small spread of availability scores throughout institutions was also depicted. Larger distributions of scores were observed at universities because of a wider variety of outlet types available in comparison with the independent takeaway outlets and vending machines at TAFE. The lack of availability of healthy food on campus is of concern because students' purchases are usually restricted to the campus offerings. Our current findings indicate that unhealthy purchases are the easiest choices when in a health-promoting food environment the converse is required - that healthy is easier to buy. Dietary behaviours of young adults could be positively influenced by healthy modifications to the environment that would allow them to make healthy food choices. Evidence shows that increasing availability and variety of healthy foods such as fruits, vegetables and reduced-fat snack foods may increase the sales within these targeted food types ${ }^{(30,35)}$. Interventions aimed at the expansion of healthier snack items $(<600 \mathrm{~kJ} /$ serve $)$ and fruit- and vegetable-rich foods within examined institutions should, therefore, be implemented.

High-scoring outlets were mainly shaped by a lower accessibility to less-healthy products rather than availability of healthy foods. Strategic placement of products in outlets can influence choice, as an increased need of effort to obtain unhealthy food items such as chips and confectionery saw a reduced consumption of these products and a concurrent increase in the purchasing of alternative items such as fruits ${ }^{(30)}$. In-store accessibility such as shelf space/length devoted to unhealthy items such as sugar-sweetened beverages may also have an impact on the healthfullness of customers' diets ${ }^{(36)}$. It is therefore important that future interventions not only focus on ensuring that healthier alternatives are made more readily available, but that effort is made to simultaneously alter accessibility of less-healthy foods ${ }^{(37)}$.

The promotions in the outlets and vending machines were commercial branding and product ranges. No evidence was found for promotion of healthy items. Studies examining the effects of promotion strategies on purchasing behaviour have reported an increase in healthy food consumption. The addition of labels and signage promoting low-fat snack choices has a significant effect on their sale and can stimulate consumer awareness and preference for healthy foods ${ }^{(1,32,35)}$. Future research is required to test point-of-purchase strategies and identify their effect on the sales of healthy and unhealthy food and drinks.

The distribution of food environment scores across availability, accessibility and promotion was not the same across different categories of food outlet types. Convenience stores and vending machines scored most poorly. These outlets consistently scored the lowest because of their provision of easily accessible, high-energy snacks and beverages, use of posters and signage promoting unhealthy foods and strategic price promotions to sell them such as two-for-one deals. Although the institutional food outlets were run by different student unions and/or food service managements, all had the same vending machine supplier. Franchise takeaway stores consistently scored the highest among the three outcome 
measures because of their selectively healthier food chains across campuses, which focused on the sale and promotion of sandwiches, salads and juices, but this is not applicable to franchise takeaway beyond the scope of tertiary-education settings. Franchise takeaway stores such as Subway produced slightly more positive scores. All scores remained low in comparison with the possible maximum score for promotion, indicating a limited promotion of healthy foods across all institutions.

This study used a quantitative survey instrument to collect detailed information about food and drink availability, accessibility and promotion and evaluated food outlets in tertiary-education settings. The audit tool covered a suitable range of food categories and environmental constructs to assess the food environment and can successfully be applied to other settings including workplace and neighbourhood. However, some limitations were encountered throughout the study. The absence of an alcohol component on the audit tool led to some discrepancies in the high rank of bars/pubs notwithstanding their perceived unhealthy nature. Assessing the price of products as a fourth outcome measure would have provided additional valuable information about the tertiary-education food environment; however, there was difficulty in data collection including unlisted prices. The study was able to determine associations between outlets and food exposure to inform change; however, it could not determine associations between food environments and food purchasing behaviour. Furthermore, the binary scoring system of the audit tool meant that results were based simply on the presence of products and failed to take into account the volume and variety of products available, therefore allowing outlets with a large variety of the same product to score the same as an outlet with a small variety. The use of a scaling system for availability may prove practical in determining the level of impact of product density. Audits were conducted over four different time points with varied seasons, and thus there is potential for seasonal differences in foods available/ changes to product lines stocked. Data on dietary habits from a large sample of young adults should be investigated with qualitative interviews with students to determine environmental influences on food purchases in future studies. This will lead to an indepth understanding of the nature of organisational food environments that young adults are exposed to, the contribution of the food environment to overall diet and how and why the food environment impacts on dietary choices.

\section{Conclusions}

Healthy food environments have been recognised as an opportunity for encouraging the purchase and consumption of healthy products among young adults. Tertiary-education institutions such as universities and TAFE are an ideal setting to implement such changes as they have an array of food outlets and policy interventions may be easier to implement than in commercially owned settings. The trends identified through this audit of the healthfullness of on-campus stores across seven campuses show that all campuses need more healthy outlets, and there are a few differences between different types of food outlets and institution types. The nature of the on-campus food environment in tertiary-education settings and its effect on students' purchasing decisions and dietary behaviour require further investigation.

\section{Acknowledgements}

We thank all the participating university food vendors for allowing us to audit their food outlets. This research received no specific grant from any funding agency, commercial or not-forprofit sectors.

Author contributions were as follows: R. R., L. H., T. D. G., E. M. F., M. S. and S. V. coordinated data collection; R. R., L. H., B. K. and T. D. G. contributed to the study design, data analysis and writing and reviewing of the manuscript; R. R., L. H. and B. K. contributed to the statistical analysis and reviewing of the manuscript; M. A.-F. contributed to the study design, data analysis and writing and reviewing of the manuscript.

The authors have declared that no conflicts of interest exist.

\section{Supplementary material}

For supplementary material/s referred to in this article, please visit http://dx.doi.org/doi:10.1017/S0007114516000568

\section{References}

1. Story M, Kaphingst KM, Robinson-O'Brien R, et al. (2008) Creating healthy food and eating environments: policy and environmental approaches. Annu Rev Public Health 29, 253-272.

2. Glanz K, Sallis JF, Saelens BE, et al. (2005) Healthy nutrition environments: concepts and measures. Am J Health Promot 19, 330-333 ii.

3. Ni Mhurchu C, Vandevijvere S, Waterlander W, et al. (2013) Monitoring the availability of healthy and unhealthy foods and non-alcoholic beverages in community and consumer retail food environments globally. Obes Rev 14, Suppl. 1, 108-119.

4. Kelly B, Flood VM \& Yeatman H (2011) Measuring local food environments: an overview of available methods and measures. Health Place 17, 1284-1293.

5. Horacek TM, Erdman MB, Reznar MM, et al. (2013) Evaluation of the food store environment on and near the campus of 15 postsecondary institutions. Am J Health Promot 27, e81-e90.

6. Horacek TM, Erdman MB, Byrd-Bredbenner C, et al. (2013) Assessment of the dining environment on and near the campuses of fifteen post-secondary institutions. Public Health Nutr 16, 1186-1196.

7. Byrd-Bredbenner C, Johnson M, Quick VM, et al. (2012) Sweet and salty. An assessment of the snacks and beverages sold in vending machines on US post-secondary institution campuses. Appetite 58, 1143-1151.

8. Higher Education Statistics Agency (2015) Student introduction 2013/14. https://www.hesa.ac.uk/content/view/3484/ \#age (accessed 12 January 2016).

9. The Chronicle of Higher Education (2014) Chronicle of Higher Education, facts \& figures, 15 May. http://chronicle.com/ article/Enrollment-Drops-08-Over/146567/ (accessed January 2016).

10. Australian Bureau of Statistics (2012) 6227.0-Education and work. http://www.abs.gov.au/AUSSTATS/abs@.nsf/DetailsPage/6227. 0May\%202012?OpenDocument (accessed 14 January 2013).

11. Allman-Farinelli MA, Chey T, Bauman AE, et al. (2008) Age, period and birth cohort effects on prevalence of overweight and obesity in Australian adults from 1990 to 2000. Eur J Clin Nutr 62, 898-907. 
12. Betts NM, Amos RJ, Georgiou C, et al. (1995) What young adults say about factors affecting their food intake. Ecol Food Nutr 34, 59-64.

13. Allman-Farinelli M (2015) Nutrition promotion to prevent obesity in young adults. Healthcare 3, 809.

14. Larson NI, Neumark-Sztainer DR, Harnack LJ, et al. (2008) Fruit and vegetable intake correlates during the transition to young adulthood. Am J Prev Med 35, 33-37.

15. Freeman B, Kelly B, Vandevijvere S, et al. (2015) Young adults: beloved by food and drink marketers and forgotten by public health? Health Promot Int pii, dav081.

16. Miller PE, Reedy J, Kirkpatrick SI, et al. (2015) The United States food supply is not consistent with dietary guidance: evidence from an evaluation using the Healthy Eating Index2010. J Acad Nutr Diet 115, 95-100.

17. Kirkpatrick SI, Reedy J, Kahle LL, et al. (2014) Fast-food menu offerings vary in dietary quality, but are consistently poor. Public Health Nutr 17, 924-931.

18. Kirkpatrick SI, Reedy J, Butler EN, et al. (2014) Dietary assessment in food environment research: a systematic review. Am J Prev Med 46, 94-102.

19. Guenther PM, Casavale KO, Reedy J, et al. (2013) Update of the Healthy Eating Index: HEI-2010. J Acad Nutr Diet 113, 569-580.

20. Glanz K, Sallis JF, Saelens BE, et al. (2007) Nutrition Environment Measures Survey in Stores (NEMS-S): development and evaluation. Am J Prev Med 32, 282-289.

21. Saelens BE, Glanz K, Sallis JF, et al. (2007) Nutrition Environment Measures Study in Restaurants (NEMS-R): development and evaluation. Am J Prev Med 32, 273-281.

22. Oldenburg B, Sallis JF, Harris D, et al. (2002) Checklist of Health Promotion Environments at Worksites (CHEW): development and measurement characteristics. Am J Health Promot 16, 288-299.

23. National Cancer Institute (2014) Measures of the food environment. https://riskfactor.cancer.gov/mfe (accessed 7 June 2014).

24. Australian Education Network (2016) Australian universities guide. http://www.australianuniversities.com.au/ (accessed 12 January 2016).

25. Technical and Further Education (TAFE), New South Wales (NSW) (2007) TAFE NSW statistics. http://www.dec. nsw.gov.au/detresources/TAFEStats_2007_dHLilTcotM.pdf (accessed April 2015).
26. Australian Bureau of Statistics (2013) Socio-Economic Indexes for Areas (SEIFA): Table 2. State Suburb (SSC) Index of Relative Socio-Economic Advantage and Disadvantage, 2011. Canberra: ABS.

27. Kelly B, Flood VM, Bicego C, et al. (2012) Derailing healthy choices: an audit of vending machines at train stations in NSW. Health Promot J Austr 23, 73-75.

28. Glanz K, Bader MD \& Iyer S (2012) Retail grocery store marketing strategies and obesity: an integrative review. $A m \mathrm{~J}$ Prev Med 42, 503-512.

29. Bustillos B, Sharkey JR, Anding J, et al. (2009) Availability of more healthful food alternatives in traditional, convenience, and nontraditional types of food stores in two rural Texas counties. JADA 109, 883-889.

30. Glanz K \& Hoelscher D (2004) Increasing fruit and vegetable intake by changing environments, policy and pricing: restaurant-based research, strategies, and recommendations. Prev Med 39, Suppl. 2, S88-S93.

31. NSW Health (2006) NSW Healthy School Canteen Strategy: Evaluation Report 2005. Sydney: State Government of New South Wales. http://www.health.nsw.gov.au/pubs/2006/pdf/ canteens_eval.pdf

32. French SA, Jeffery RW, Story M, et al. (2001) Pricing and promotion effects on low-fat vending snack purchases: the CHIPS study. Am J Public Health 91, 112-117.

33. Matthews MA \& Horacek TM (2015) Vending machine assessment methodology. A systematic review. Appetite 90, 176-186.

34. Grech A \& Allman-Farinelli M (2015) A systematic literature review of nutrition interventions in vending machines that encourage consumers to make healthier choices. Obes Rev 16, 1030-1041

35. Seymour JD, Yaroch AL, Serdula M, et al. (2004) Impact of nutrition environmental interventions on point-of-purchase behavior in adults: a review. Prev Med 39, Suppl. 2, S108-S136.

36. Farley TA, Rice J, Bodor JN, et al. (2009) Measuring the food environment: shelf space of fruits, vegetables, and snack foods in stores. J Urban Health 86, 672-682.

37. Roy R, Kelly B, Rangan A, et al. (2015) Food environment interventions to improve the dietary behavior of young adults in tertiary education settings: a systematic literature review. J Acad Nutr Diet 115, 1647-1681. 